Indonesian Journal of EFL and Linguistics

Vol. 2 No. 2, 2017

eISSN: 2503-4197, pISSN: 2527-5070

www. indonesian-efl-journal.org

\title{
BBC Radio Drama Series Cabin Pressure: Abu Dhabi for Giving Listening Exposure to Students: A View from Humour Perspective
}

\author{
Anastasia Nelladia Cendra \\ Sanata Dharma University, Indonesia \\ e-mail: anelladiahp@gmail.com
}

\begin{abstract}
:
Using authentic materials to give listening exposure is essential to improve English language learners' listening skill and using radio is one way to do so. To reduce anxiety in listening, choosing humorous material can be done as humour has been proven beneficial in classroom context, for example, in reducing stress. Using the partial result of a study conducted by the same author and completed by library study about ethics of using humour in the classroom, this study is to investigate whether verbal humour found in BBC Radio Drama Series Cabin Pressure: Abu Dhabi is suitable to be used in classroom context. Analysing every type verbal humour found in the radio drama, this study points out that verbal humour found in BBC Radio Drama Series Cabin Pressure: Abu Dhabi is generally not appropriate to be used in classroom because it has a quite high number of inappropriate verbal humour, such as sarcasm and satire.
\end{abstract}

Keywords: listening exposure, verbal humour, appropriateness 


\section{INTRODUCTION}

Learning English involves learning four skills: listening, speaking, reading, and writing. Ridel (2003) argues that among these skills, listening is considered the hardest skill to be learnt (as cited in Hapsari \& Ratri, 2013). To overcome this, it is suggested that authentic materials of listening are given to the students, even from the beginning of a language course, in order to give the students benefits of naturalness and real-life listening experience; listening to authentic materials exposes students with natural accent, speed, and meaning (Field, 2002). Exposure to authentic listening material will make the students accustomed to listening to realworld English. This kind of exposure in listening will likely to make the students get used to listening to the target language and generally improve their listening skill.

However, students are usually afraid of listening to authentic materials. (Hapsari \& Ratri, 2013). It can be caused by students' lack of familiarity to the accents and speech speed of the speakers. Some students may be unprepared and lost in confusion. Nevertheless, it is should be really emphasized from the beginning that the goal is not to understand the whole recording and its little details (Hapsari \& Ratri, 2013), but to focus on giving exposure to make students accustomed to how real-world listening is like.

Speaking about authentic materials, radio is one of the media that can be used to give authentic listening exposure to students. It has been known from a long time that radio may become a media for learning English. Even, in the time around World War II, there was such interest in a lot of countries to listen to the radio while learning English through BBC broadcasts (Howse, 1979). Listening to radio programmes in English will eventually influence someone's ability in listening. In addition, audio programs can fulfil the need of providing learning materials that bring English live for the students, as what English teachers all over the world dream over (Tomalin, 1979). Many broadcasts in radio, either scripted or unscripted can also be used as English learning materials (Dunkling, 1979). It has been known that even more advanced programme can still be useful for more advanced learner to help them keep up their knowledge of the language (Tomalin, 1979). Furthermore, it has been known that if the language programmes in radio are selectively used, the learning will become more effective and meaningful and students' mastery in vocabulary and pronunciation can be increased (Odera, n.d.).

Selecting appropriate listening materials, by no means, is an easy task. There are so many considerations that the teacher should make in selecting the listening materials to give listening exposure to the students. Apart from the content of the material, teachers should also be smart in choosing the materials for the students that may reduce students' anxiety in listening, as it has been explained that students may be daunted by authentic listening materials. One that can be done is by using humour in giving the listening exposure.

There is a growing body of research that emphasises the importance of using humour in the classroom. The use of humour in the classroom may able to create a more conducive environment for classroom activity and help students learn the 
material easier and more efficient (Pham, 2014). In addition, humour experiences can also provide positive emotions to enhance attention in learning (Krause, 2014). Krause also summarizes that in EFL classroom context, humour can also help reduce students' anxiety in learning the target language so that the students will be more engaged with the learning (Krause, 2014). Furthermore, it is also believed that humour may reduce many student' disruptions. In the same light, humour in many ways can be the direct ammunition for students rooted in anger, anxiety, and low self-esteem (Goebel, 1958). Thus, it is safe to say that humour brings positive vibes for teaching-learning activity in the classroom.

BBC Radio Drama Series Cabin Pressure: Abu Dhabi is a radio drama based on everyday talk that can be used to give exposure of English to students in enjoyable way. It also provides students with authentic English, spoken by native speakers. The sound produced is also clear. Moreover, the fact that the radio drama is humorous might give positive reinforcement that makes the learning more fun.

Based on the background, BBC Radio Drama Series Cabin Pressure: Abu Dhabi might be the perfect source to give English exposure for students in learning English as a foreign language. This research, however, aims to investigate whether the verbal humour found in BBC Radio Drama Series Cabin Pressure: Abu Dhabi is appropriate for English language teaching.

\section{LITERATURE REVIEW}

\subsection{Verbal Humour and Its Types}

Before going on deeper about verbal humour, it would be better if we understand humour first. Humour can be defined as something funny that elicits laughter, smiles, or amusement. However, some problems arise when we want to define humour. Some people may laugh at something; some people may only smile. Yet, the others do not even find it funny at all. Indeed, humour is a difficult concept to describe. Nevertheless, in general, humour refers to anything that is funny, either intended or not intended (Jay, 2003).

Humour can be categorized into four major classification, namely (1) figural humour, which involves the use of drawing, (2) visual humour, which uses visual cues, (3) auditory humour, which uses auditory cues, and (4) verbal humour, that depends on the language use (Shade, 1996). BBC Radio Drama Series Cabin Pressure: Abu Dhabi is a radio drama programs that uses a lot of verbal humour, as it is served in radio medium that limits the use of visual media. Thus, the humorous situations and jokes presented depend on the effective use of language.

Verbal humour can come in many forms. There are 12 categorization of verbal humour, namely: (1) pun, that relies on a smart play of word to create ambiguous meaning or application, (2) riddle, that elicits the use of incongruent questionanswer format (3) joke, that refers to the use of multiple meaning of words, idiom, and metaphors to create sudden change of perspective, (4) satire, that refers to humorous criticism, (5) limerick, that uses five-lined nonsense verse (6) parody, which uses imitation of other works with ludicrously different theme, (7) anecdote, 
which refers to an oral account of real of fictional event, usually biographical that results in a funny short story, (8) farce, that makes use of boisterous humour, (9) irony, that makes use of the intended meaning and literal meaning, (10) sarcasm, that is similar to irony but is sharper and targeted to a certain group or individual, (11) tall tales, which can be found in stories that relies on the exaggeration to tell most facts and events surrounding the characters, setting, and plots in the story, and (12) wit, that uses the quick and spontaneous statements that connect incongruous ideas (Shade, 1996). Each of the humour presented here has their own characteristics that differ one kind of humour from the others.

\subsection{Benefits of Humour in Education}

Humour can be very beneficial for anyone. It can enhance one's physical health by improving respiration, circulation, immune system, and tolerance to pain as well as giving positive effect to mental health by helping one to reduce stress (Goebel, 2011). Another study also mentions the same thing; that humour can be "a key to controlling stress, promoting good health, and encouraging positive work relationships" to improve work experience (Black \& Forro, 1999).

In classroom, humour also provides advantages for a more positive and conducive classroom atmosphere. Many studies have been conducted on the benefits of using humour in the classroom and they generally argue that humour should be implemented in the classroom. The use of humour in classroom context can help to reduce nervousness and make students more relax yet interested and have a positive emotion in learning (Krause, 2014). In addition, humour may create a more conducive environment in learning (Pham, 2014). Furthermore, the use of humour in classroom may reduce many students' disruptions, like anger, anxiety, and low esteem that some students may have (Goebel, 1958).

Humour also gives many other advantages. It may encourage self-esteem enhancement, improve motivation in learning, reduce stress and anxiety, give health benefits to students, improve morale and team building, encourage creative and divergent thinking, avoid burnout from stress and pressure, improve instruction or communication, release tension, and give relief from classroom boredom (Shade, 1996). Thus, it is no doubt that bringing humour in the classroom may help students learn better.

\subsection{Ethics of Using Humour in Classroom}

The use of humour, especially if it is implemented in the classroom should be ethical. Some humours are considered inappropriate. In other word, humour is not always funny. If it is abusively and unethically used, humour may have the power to attack the target (Benatar, 2014). In addition, humour can be effective if it is gradually introduced, intentionally planned and executed, and mutually enjoyed (Shade, 1996). Thus, in using humour in the classroom, teachers should be careful.

There are some types of humour that should be avoided, especially in classroom context. Racial and gender, religious, scatological, sexual, sick, hostile, and setting up people to misfortune humour should not be implemented in the classroom 
(Benatar, 2014). Racial, ethnic and gender humour that attacks specific groups, people, or individual is considered inappropriate. Humour about God and other religious figure such as Jesus and Mohammed are also not suggested as it can be considered as blasphemous humour. Scatological humour, humour that focus on private parts, sex, urination, defecation, and other bodily fluids, is also considered inappropriate. Humour that uses death and suffering as its main concern to gain laughter is also not recommended. Another categorisation humour that raises concerns of its ethic is humour about people's personal attributes or their mental strategies. In the end, setting up people in a certain situation that causes their misfortune without their acknowledgment for source of laughter is also considered unethical.

There are also some caveats when using humour in the classroom. Distractive, hostile, ridicule, satire, cynicism, and sarcasm humour are better avoided in classroom context (Shade, 1996). Distractive humour is not recommended in the classroom as it can distract the students from the topic or materials discussed. Hostile humour, as it has been explained before, should be avoided because it is often non-productive and punishing all involved. Furthermore, it may indicate one's superiority while putting others down. Ridicule also should not be included in the classroom because it generally mocks and makes fun of the target. Satire humour, that is used to criticize and ridicule the target is also considered inappropriate. Cynicism humour is also considered unsuitable as it promotes disbelief in God. In the end, sarcasm is not suggested in classroom context as it is brutal and may results in poor attitudes and deep resentment (Shade, 1996).

In short, teachers should avoid these types of humour because they may be harmful if infused in the classroom. In addition, teachers also should discourage the use of these humour by students as they lead to bad taste and poor judgement (Shade, 1996). Teachers, indeed, should be very careful in using and implementing humour in the classroom.

\section{RESEARCH METHODOLOGY}

This study uses the partial result of a research conducted by the same author entitled "A Linguistic Analysis of Verbal Humour Found in BBC Radio Drama Series Cabin Pressure: Abu Dhabi" (see Cendra, 2016) as the data resource. The data used in the present study was taken from the first research question in the study that concerns about the types of verbal humour found in BBC Radio Drama Series Cabin Pressure: Abu Dhabi.

In addition, this research also employs library study to find some books, journals and article that can help the researcher investigate the formulated problem and find the answers of the problem. The books, journal, and articles are studied and used to analyse the data. They provide the researchers with ample suggestions on the ethics of using humour in the classroom.

The data collected in the study will be categorized based on the verbal humour categorization, and will be analysed using the theory for each category. Because of the sheer size of the verbal humour found and the page constraint, only one example 
for each category will be presented and elaborated in this study. In the end, some recommendations will be drawn related to whether or not the verbal humour found within BBC Radio Drama Series Cabin Pressure: Abu Dhabi is implementable in classroom context for giving authentic exposure to improve listening skill.

\section{FINDINGS}

\subsection{Overview of BBC Radio Drama Cabin Pressure: Abu Dhabi}

Cabin Pressure: Abu Dhabi is the title of the first episode of the first series of radio situation comedy drama series broadcasted by BBC Radio 4. The drama is set in airplane and airport settings, telling day-to-day experience of the oddball crews of a small airplane charter, MJN Air. The radio drama is starred by four main characters, the pilot, the co-pilot, the steward, and the CEO.

The episode opens up when Carolyn, the CEO of MJN Air, prohibits the captain, Martin, from diverting and spending a lot of money. It is because he has flown a very expensive flight to Bristol prior the flight. While flying to Abu Dhabi, Douglas, the co-pilot, notices that a client's cat is left in the unheated hold, and therefore, the cat is dying. Martin becomes confused whether he has to divert to save the cat or not. Meanwhile, Arthur, the steward and also the son of the CEO, tries to learn how aero planes fly.

This story is wrapped within clear and good quality audio. In addition, the speed, accent, and the pronunciation is also natural as the radio drama is produced for every listener; not intentionally for learning purpose that uses used slowed down speed and very clear pronunciation. It can be concluded that the radio drama is an entertainment program for all listeners, not just for English learners.

\subsection{Verbal Humour Found}

There are 67 verbal humours found in BBC Radio Drama Series Cabin Pressure: Abu Dhabi that fall into nine categories. The other three categories, namely limerick, parody, and anecdote has zero appearance (see Cendra, 2016). Figure 4.1 is the statistic of the verbal humour found in the radio drama.

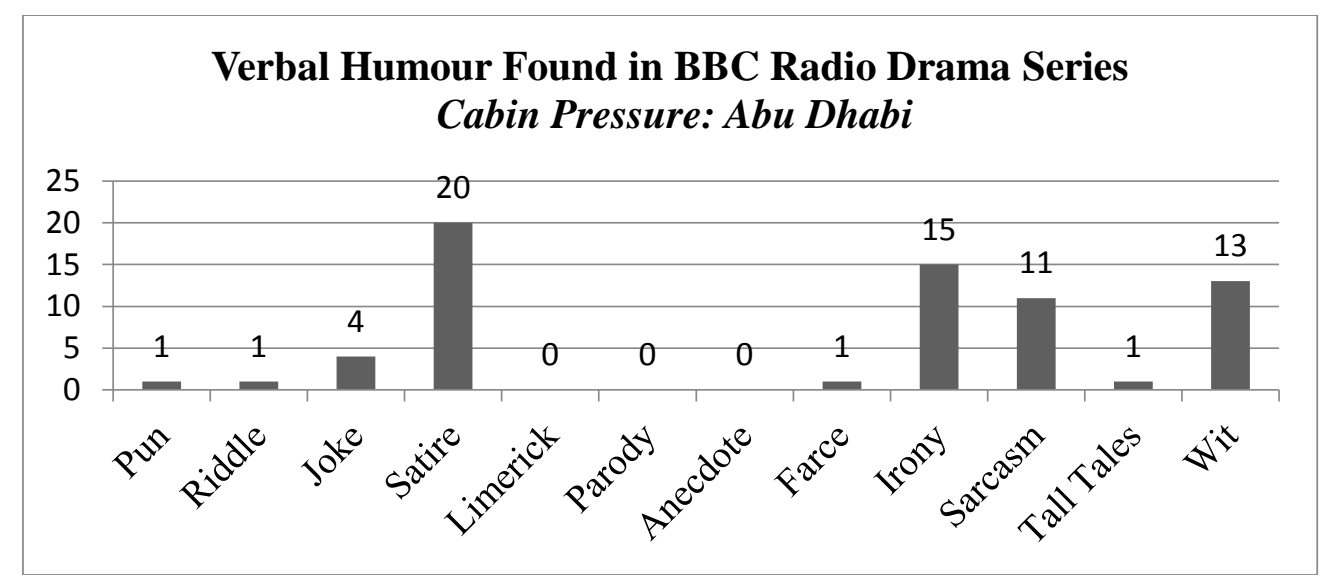

Figure 4.1 Verbal Humour Found in BBC Radio Drama Series Cabin Pressure: Abu Dhabi (see Cendra, 2016) 
Based on the findings on the previous study, the present research is attempting to investigate the appropriateness of using BBC Radio Drama Series Cabin Pressure: Abu Dhabi as ELT material in teaching. The following parts will discuss the humour found for each category along with the discussion of its appropriateness in classroom context.

\subsubsection{Pun}

Pun is a type of humour that relies on word play to suggest different meaning and application (Shade, 1996). Only one pun is found in the radio drama in minute 00.02.00 (Cendra, 2016), presented as follows.

Arthur : Oh, who's that guy? Um, oh, grey haired, did that game show, "Can I have a P, please, Bob?"

If observed closely, the only pun in the radio drama relies on the play of the word "P", that suggest different meaning between the letter " $P$ " itself and the word "pee" as they have exactly the same pronunciation, /pi:/, in order to elicits laughter. This, unfortunately, formulates slightly scatological humour that make fun of bodily fluid (Benatar, 2014), which is urination. Thus, this humour may not be appropriate in the classroom context.

\subsubsection{Riddle}

Riddle is verbal humour presented in a question and answer format which includes puzzling facts (Shade, 1996). One riddle is found in 00.16.24 in the radio drama, as follows (Cendra, 2016).

\section{Martin : Why would he want a storage heater in Abu Dhabi? \\ Douglas : Well, there is a lot of heat to store}

The riddle presented here uses question and answer format to provide puzzling facts in order to create humorous situation for the audience. Thoroughly observed, the one and only riddle in the radio drama is not harmful to be implemented in the classroom setting. It is because it does not have the "butt of the joke" or the target. As a result, the humour does not have the potential to hurt someone's feeling. In addition, the content of the humour is also not included to the types of humour that should be avoided in the classroom as it concerns about puzzling facts only.

\subsubsection{Joke}

Joke uses multiple meaning of words, idiom and metaphors; ambiguity; incongruity; or sudden change of perspective to provoke laughter (Shade, 1996). In the study, there are 4 jokes found that belongs to deep structured joke (Cendra, 2016). The following is one example, taken from minute 00.03.15.
Douglas : Do you know, Martin, all these years and I've never been to Bristol?
Martin : We'll get ready for a treat.
Douglas : I don't know. I was rather hoping not to break my duck. 
The joke presented here uses idiom break my duck, which means doing something for the first time, to elicit laughter. Thoroughly observed, the joke here is also appropriate to be used in classroom. It is because this joke does not have the target of the joke. Furthermore, the content of the joke also is not included in any 'forbidden' humour that is considered unethical for classroom context. Doing similar thing to the other three jokes, the researcher finds that the other jokes are also safe for classroom environment.

\subsubsection{Satire}

Satire is one verbal humour that is used to criticize someone that often involves exaggeration, distortion, and understatement (Shade, 1996). There are 20 humours that fall into satire category found in the radio drama, becoming the most frequent type of humour that appears in the radio drama (Cendra, 2016). One satire is taken from minute 00.08.21 to be discussed here.

Carolyn :So listen, next Thursday, you are going to Abu Dhabi, and you are going cheap. You will fly the most no-frills, most cost-effective plane it is possible to fly. You will make easy jet look like Air Force One. Understood?

$$
\begin{aligned}
\text { Martin } & : \text { Yes, Carolyn. } \\
\text { Douglas } & : \text { And who are the lucky passengers on Scrooge McDuck } \\
& \text { Air? }
\end{aligned}
$$

The satire presented here is about how Douglas criticizes his CEO, Carolyn, of being so stingy by calling her airline business as Scrooge McDuck Air. Unfortunately, this humour is not really applicable in classroom context as it belongs to satire. As Shade (1996) mentions, satire mainly concerns in criticizing someone and it belongs to one type of humour that is better avoided in classroom context. Based on this theory, the rest 19 satire humours found in this study are considered inappropriate in classroom context.

\subsubsection{Farce}

Boisterous humour is the main characteristic of a farce (Shade, 1996). Based on that definition, only one farce is found in the very beginning of the radio drama, minute 00.00.00 (Cendra, 2016).

Douglas : Good evening, ladies and gentlemen, First Officer Douglas Richardson here. Just to let you know, we're making our final approach now into what I am fairly sure is Fitton airfield...unless it's a farm... or just possibly the A45. It's not the sea, because that's blue. I should perhaps explain that Captain Crieff and I have a sportsman-like little bet on today about who can fly the best after drinking a litre of Vodka through a straw. The Captain went first. You may have noticed the takeoff run was a little bumpy, particularly over the golf 
course. Now it's me to land, just as soon as I decide, which of these two runaways to aim for. And I'm happy to tell you that I feel lucky. So, on behalf of all your crew today, may I just say, geronimo!

The farce found in the radio drama tells about how the first officer of MJN Air does a monologue where he is pretending that he is not sure where to land the airplane after drinking a litre of vodka. As the farce presented here does not have a target of the humour and does not violate the ethics of humour in the classroom, the farce is considered applicable to be used in classroom context.

\subsubsection{Irony}

Verbal humour irony is defined as humour that uses opposite speech from literal meaning (Shade, 1996). In the radio drama, there are 15 pieces of irony found, becoming the second most frequent verbal humour appeared in the radio drama (Cendra, 2016). One sample of irony, taken from minute 00.22.09, is discussed here.
Martin : Do you think it's dead?
Douglas : No, no, definitely not. Not yet.

The verbal humour irony presented tells about Martin's doubt if it (the dying client's cat) is dead already. Then, Douglas assures that the cat is definitely not dead and, thus, would survive the flight. Nevertheless, a second later, Douglas continues "not yet", hinting that the cat is dying and would die immediately. The irony sample presented here is still considered appropriate for classroom context. It is due to the fact that, although irony uses the opposite speech of the intended meaning, it is not produced to hurt, mock, or ridicule others. In addition, the content of irony here does not make use of sensitive topics that should be avoided in classroom context. Doing the same observation for the rest 14 pieces of irony collected within the radio drama, the researcher does not find any irony that violate the ethic of the use of humour in the classroom.

\subsubsection{Sarcasm}

Sarcasm is a type of verbal humour that is used to give taunt, scoffing jibe, or veiled sneer, which has a potential to hurt the target of the humour (Shade, 1996). There are 11 humours in the radio drama that fall into this category. One sample, found in minute 00.13 .32 is discussed here.

Martin : Don't call me Sir, Douglas.

Douglas : Sir's mind is fickle and changeable. I shall endeavour to remember, Sir, but from time to time, my natural awe at the majestic figure cut by Sir may bubble up, uncontrollably here. 
The verbal humour presented in this part is when Douglas sarcastically calls Martin Sir to show how, in Douglas's opinion, Martin does not deserve to be called Sir. Unfortunately, as it has a potential to hurt someone's feeling, sarcasm is not really recommended to be used in a classroom context. As Shade (1996) explains, because it may be brutal and results in poor attitudes and deep resentment, sarcasm is not recommended to be used in classroom context. In addition, humour that attacks specific groups or individual is considered inappropriate for classroom context (Benatar, 2014). Thus, all 11 sarcasm verbal humours found in the radio drama are considered inappropriate for classroom context.

\subsubsection{Tall Tale}

Tall tale refers to verbal humour that is marked by the use of exaggeration to tell the most facts presented in order to elicits laughter from the audience (Shade, 1996). Only one tall tale presents in the radio drama (Cendra, 2016). The following is the tall tale found in minute 00.22.56.

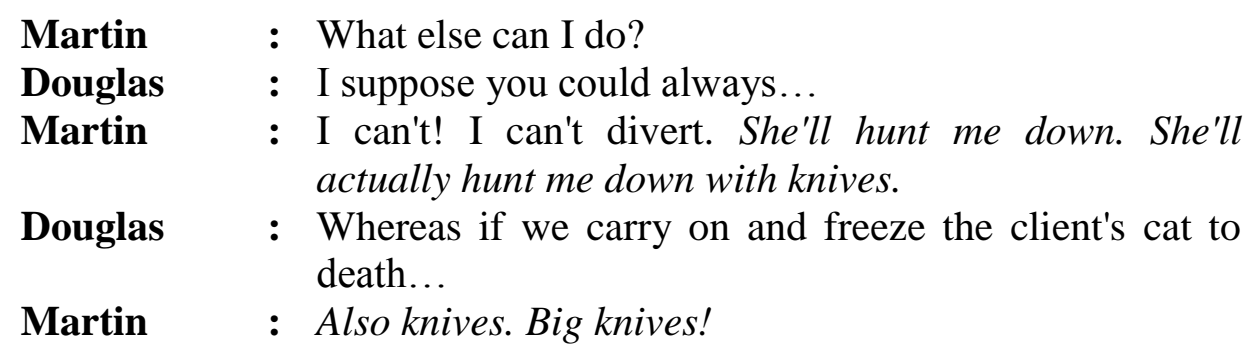

The short tall presented here tells about the way Martin exaggerates the possibility of how Carolyn will treat him if he chooses to divert. He explains the way Carolyn might hunt him down with knives, which is very unlikely to happen. This kind of humour is considered acceptable in classroom context, as it does not have the "butt of the joke" and will not hurt other's feeling. In addition, the context of the verbal humour presented does not belong to categories of humour that should be avoided in classroom.

\subsubsection{Wit}

Wit is a type of verbal humour that relies on the ability to intelligently connect two incongruous ideas, resulting in quick and out of the cuff statement (Shade, 1996). In the radio drama, 13 verbal humours that falls into this category are collected (Cendra, 2016). The following is one sample of wit appeared in minute 00.17.47.

Arthur : Why does the air on the top have to keep up the air at the bottom? Why don't they just... split up?

Douglas : For the sake of the kids?

In this wit, Douglas successfully connects two different ideas: the air around the airplane wings and marriage. He deliberately and quickly answers Arthur's question using different and incongruous ideas to elicit laughter. Observing the context of the humour, this wit is still appropriate to be used in 
a classroom. In addition, the fact that the humour is not targeted to specific groups or individuals make the wit presented safe for classroom use. Doing the same thing for the rest of the wit collected, the researcher considers all 13 pieces of wit are safe for classroom context.

\section{DISCUSSION}

As explained, there are 67 verbal humours that have been collected within BBC Radio Drama Series Cabin Pressure: Abu Dhabi. They fall into different nine (out of twelve) categories of verbal humour (see Cendra, 2016). The present findings show that some verbal humours are considered appropriate to be used in classroom context where some other are not. Table 4.1 summarises the findings of the present study.

Table 4.1 Summary of Appropriate and Inappropriate Verbal Humour for Classroom Context found in Cabin Pressure: $\mathrm{Abu}$ Dhabi

\begin{tabular}{clccc}
\hline No & Types & Total & Appropriate & Inappropriate \\
\hline $\mathbf{1}$ & Pun & 1 & 0 & 1 \\
$\mathbf{2}$ & Riddle & 1 & 1 & 0 \\
$\mathbf{3}$ & Joke & 4 & 4 & 0 \\
$\mathbf{4}$ & Satire & 20 & 0 & 20 \\
$\mathbf{5}$ & Farce & 1 & 1 & 0 \\
$\mathbf{6}$ & Irony & 15 & 15 & 0 \\
$\mathbf{7}$ & Sarcasm & 11 & 0 & 11 \\
$\mathbf{8}$ & Tall tale & 1 & 1 & 0 \\
$\mathbf{9}$ & Wit & 13 & 13 & 0 \\
& Grand Total & 67 & 35 & 32 \\
\hline
\end{tabular}

Referring to table 4.1 , it is safe to say that the number of inappropriate verbal humour found in BBC Radio Drama Cabin Pressure: Abu Dhabi is relatively high; it is almost the half of all verbal humour found. Giving the fact that we cannot skip the radio drama series to choose only the appropriate form of verbal humour without giving away the flow of the story, the researcher considers that BBC Radio Drama Series Cabin Pressure: Abu Dhabi is not recommended to be used in classroom context.

If observed carefully, the context of verbal humour found in BBC Radio Drama Series Cabin Pressure: Abu Dhabi almost does not have problems with the ethics of using humour proposed by Benatar (2014), which forbids the use of racial and gender, religious, scatological, sexual, sick, hostile, and setting up people to misfortune humour. Only one pun that slightly touches the ambiguous meaning between the word $\mathrm{P}$ and pee, is considered inappropriate. Unfortunately, BBC Radio Drama Series Cabin Pressure: Abu Dhabi are using a lot of sarcasm and satire, two forms of verbal humour that should be avoided for classroom context according to Shade (1996). Satire is not recommended as it is used to criticize and ridicule the target of the humour where sarcasm is not suggested in classroom context as it is brutal and may results in poor attitudes and deep resentment (Shade, 1996). Thus, it 
is hard to recommend this radio drama to be used in giving authentic listening exposure of English in classroom context.

However, all verbal humours in the radio drama, especially the sarcasm and satire humour, are targeting the characters of the radio drama. The audience, in this case is learners, is not the target of the sarcasm and satire. Based on this consideration, the researcher hypotheses that BBC Radio Drama Series Cabin Pressure: Abu Dhabi might still be applicable as the authentic materials to give English language exposure for more adult learners. However, further research is strongly needed to prove this hypothesis.

\section{CONCLUSION, IMPLICATIONS AND LIMITATIONS}

In conclusion, analysed from humour perspective, BBC Radio Drama Series Cabin Pressure: Abu Dhabi is not suitable to be used for giving English exposure for students. It is because the radio drama contains many inappropriate humours for classroom context, such as a high number of satire and sarcasm.

Using humour is always advisable in classroom. Many researchers have proven the benefits of inducing humour in classroom context (see Benatar, 2014; Goebel, 2011; Black \& Forro, 1999; Krause, 2014). However, teachers should be careful in choosing the resources and the forms of humour to make sure they bring only the positive sides to their students.

The same principle applies in choosing materials for students. Choosing humorous authentic material might be a good idea. However, the teachers have to make sure that the humour is applicable for classroom context (see Benatar, 2014; Shade, 1996). Although the study cannot be an account for generalization, the study has provided some insight of what types of humour that can and cannot be implemented in classroom.

Nevertheless, some limitations are unavoidable in conducting a research. The researcher acknowledges that some limitations present in the study. First of all, the researcher has a very limited time is conducting this research because of a personal reason. This time constraint, like it or not, will affect the depth analysis of the study. Furthermore, the data presented in the study is not supported by other form of data, such as students' or teachers' perspective on the ethic of using humour in classroom. Thus, researcher's bias might present in this study. The researcher, however, has tried to be neutral in analysing the data presented in the study.

After all, this study has given a glimpse of how to analyse authentic listening materials from humour perspective. The researcher hopes that other researcher would conduct a further research about this, as the topic is fairly new. Expanding the knowledge of how to choose the suitable authentic materials for teaching would surely benefits many EFL educators. 


\section{REFERENCES}

Benatar, D. (2014). Taking Humour (Ethics) Seriously, But Not Too Seriously. Journal of Practical Ethics, 25-23. Retrieved September 5, 2017, from http://www.jpe.ox.ac.uk/wp-content/uploads/2014/06/JPE0009-Benatar.pdf

Black, L., \& Forro, D. (1999). Humor in the Academic Library: You Must Be Joking! or, How Many Academic Librarians Does It Take to Change a Lightbulb? College \& Research Libraries, 60, 165-172. Retrieved September 13, 2017, from http://crl.acrl.org/index.php/crl/article/view/15276/16722

Cendra, A. (2016). A linguistic analysis of verbal humour found in BBC Radio drama series Cabin Pressure: Abu Dhabi. Undergraduate Thesis, Sanata Dharma Unoverity, English Language Education Study Program.

Dunkling, L. (1979). The English teaching radio script. In The use of the media in English language teaching (pp. 31-40). The British Council Printing and Publishing Department.

Field, J. (2002). The changing face of listening. In J. Richards, \& W. Renandya (Eds.), Methodology in language teaching: An anthology of current practice (pp. 242-247). New York, United States of America: Cambridge University Press.

Goebel, B. (2011). Humor Writing:: activities for the English classroom. United States of America.: National Council of Teachers of English.

Hapsari, Y., \& Ratri, D. (2013). Extensive listening: Let students experience learning by optimizing the use of authentic materials. Universitas Brawijaya Malang, Fakultas Ilmu Budaya. Retrieved September 19, 2017, from http://fib.ub.ac.id/wrp-con/uploads/Yulia-Hapsari-Seminar-dan-LokakaryaInternasional-FPBS-UPI-2013.pdf

Howse, H. (1979). BBC English by radio and television - An outlinr History. In The Use of the Media in English Language Teaching (pp. 15-23). London: The British Council Printing and Publishing Department.

Jay, T. (2003). The psychology of language. Upper Saddle River: Pearson Education Ltd.

Krause, R. (2014). Humour - An 'Important Spice to Use in Teaching'? On Humour and Its Uses in English as a Foreign Language Classrooms. Freie Universität Berlin, Institut für Englische Philologie. Retrieved September 5, 2017, from ttp://www.geisteswissenschaften.fu-

berlin.de/we06/engdid/ressourcen/pdfs/hausarbeiten/Humour-in-EFL-

Classrooms--Rebekka-Krause-.pdf

Odera, F. (n.d.). Learning English language by radio in primary schools in Kenya. Retrieved September 7, 2017, from https://wikieducator.org/images/8/8d/Florence_Y._Odera.pdf

Pham, H. (2014). The use of humour in EFL teaching: A case study of Vietnamese university teachers' and students' perceptions and practices. Phd Thesis, University of Canberra, Faculty of Art and Design, Australia. Retrieved September 5, 2017, from 
http://www.canberra.edu.au/researchrepository/file/f6fd3a90-c261-4768-9650556354aac708/1/full_text.pdf

Shade, R. (1996). License to laugh: Humor in the classroom. Westport: Teachers Idea Press.

Tomalin, B. (1979). Using BBC English by radio and television in the classroom. In The use of the media in English language teaching (pp. 68-74). London: The British Council Printing and Publishing Department. 